\title{
(6) OPEN ACCESS \\ Cohort study of electronic cigarette use: effectiveness and safety at 24 months
}

\author{
Lamberto Manzoli, ${ }^{1,2,3,4}$ Maria Elena Flacco, ${ }^{1,2}$ Margherita Ferrante, ${ }^{5}$ \\ Carlo La Vecchia, ${ }^{6}$ Roberta Siliquini, ${ }^{7}$ Walter Ricciardi, ${ }^{8,9}$ Carolina Marzuillo, ${ }^{10}$ \\ Paolo Villari, ${ }^{10}$ Maria Fiore, ${ }^{5}$ the ISLESE Working Group
}

- Additional material is published online only. To view please visit the journal online (http://dx.doi.org/10.1136/ tobaccocontrol-2015-052822).

For numbered affiliations see end of article.

\section{Correspondence to} Dr Lamberto Manzoli, Palazzina di Odontoiatria, University of Chieti, Via dei Vestini 5, Chieti 66100, Italy; Imanzoli@post.harvard.edu

LM and MEF equally contributed to the present study.

Received 11 November 2015 Accepted 19 April 2016 Published Online First 6 June 2016
CrossMark

$$
\begin{aligned}
& \text { To cite: Manzoli } \mathrm{L} \text {, } \\
& \text { Flacco ME, Ferrante M, } \\
& \text { et al. Tob Control } \\
& \text { 2017;26:284-292. }
\end{aligned}
$$

\section{ABSTRACT}

Objective To evaluate the safety and effectiveness of e-cigarettes, by comparing users of only e-cigarettes, smokers of only tobacco cigarettes and dual users.

Design Prospective cohort study. We update previous 12-month findings and report the results of the 24-month follow-up.

Data sources Direct contact and questionnaires by phone or via internet.

Methods Adults (30-75 years) were classified as: (1) tobacco smokers, if they smoked $\geq 1$ tobacco cigarette/day, (2) e-cigarette users, if they inhaled $\geq 50$ puffs/week of any type of e-cigarette and (3) dual users, if they smoked tobacco cigarettes and also used e-cigarettes. Carbon monoxide levels were tested in $50 \%$ of those declaring tobacco smoking abstinence. Hospital discharge data were used to validate possibly related serious adverse events in $46.0 \%$ of the sample.

Main outcome measures Sustained abstinence from tobacco cigarettes and/or e-cigarettes after 24 months, the difference in the number of tobacco cigarettes smoked daily between baseline and 24 months, possibly related serious adverse events.

Results Data at 24 months were available for 229 e-cigarette users, 480 tobacco smokers and 223 dual users (overall response rate $68.8 \%$ ). Of the e-cigarette users, $61.1 \%$ remained abstinent from tobacco (while $23.1 \%$ and $26.0 \%$ of tobacco-only smokers and dual users achieved tobacco abstinence). The rate $(18.8 \%)$ of stopping use of either product (tobacco and/or e-cigarettes) was not higher for e-cigarette users compared with tobacco smokers or dual users. Self-rated health and adverse events were similar between all groups. Among those continuing to smoke, there were no differences in the proportion of participants reducing tobacco cigarette consumption by $50 \%$ or more, the average daily number of cigarettes and the average selfrated health by baseline group. Most dual users at baseline abandoned e-cigarettes and continued to smoke tobacco. Those who continued dual using or converted from tobacco smoking to dual use during follow-up experienced significant improvements in the 3 outcomes compared with those who continued or switched to only smoking tobacco $(p<0.001)$.

Conclusions E-cigarette use alone might support tobacco quitters remaining abstinent from smoking. However, dual use did not improve the likelihood of quitting tobacco or e-cigarette use, but may be helpful to reduce tobacco consumption. Adverse event data were scarce and must be considered preliminary.

Trial registration number NCT01785537.

\section{INTRODUCTION}

Despite their potential public health relevance, the current evidence on the safety and efficacy/ effectiveness of e-cigarettes is scarce, and long-term data are urgently needed. ${ }^{1-7}$ The published prospective evidence on the efficacy/effectiveness for healthy participants consists of 2 randomised trials, ${ }^{8} 92$ single-arm small trials ${ }^{10-12}$ and 11 observational studies. ${ }^{13-23}$ However, these studies mostly included users of both tobacco and e-cigarettes followed for $\leq 12$ months, used various assessment methods, and did not directly compare e-cigarette users and tobacco smokers. ${ }^{4672425}$ Moreover, the entire evidence on e-cigarette safety-at 6 months -is limited to 122 healthy participants, most of whom were also smoking tobacco for most of the follow-up. ${ }^{8} \quad 9 \quad 11$ We previously reported the 12-month follow-up results ${ }^{26}$ of our 5-year study aimed at evaluating the long-term effects of e-cigarette use. ${ }^{27}$ We report the results of the 24-month follow-up, and include hospital discharge data.

\section{METHODS}

The protocol and 12-month results of this prospective cohort study are reported elsewhere, ${ }^{26}{ }^{27}$ and registered in Clinicaltrials.gov (NCT01785537). In brief, we recruited adults (30-75 years) who were: (1) tobacco smokers of $\geq 1$ tobacco cigarette daily for $\geq 6$ months; (2) e-cigarette users of any type of e-cigarette for $\geq 6$ months (3) dual users of tobacco and e-cigarettes for $\geq 6$ months, via general practitioners, e-cigarette shops, internet advertisements and social networks.

Data were collected through a structured questionnaire, administered through phone interview and/or by internet, and follow-up will continue up to 60 months. Two investigators (MEF and LM) tested carbon monoxide levels in expired breath (Smokerlyzer piCO+, Bedfont Scientific) in a random sample of those declaring tobacco smoking abstinence $(25 \%$ and $50 \%$ at 12 and 24 months, respectively).

The work was approved by Chieti University Ethics Committee; all participants provided written informed consent.

\section{Outcome variables and data analysis}

The primary outcome was the percentage of sustained (30 days) abstinence from tobacco smoking at 24 months. Other outcomes were the proportion of participants abstinent from both tobacco smoking and e-cigarette use, the number of tobacco 
cigarettes smoked per day (and the proportion of participants reducing tobacco cigarette consumption by $50 \%$ or more between baseline and 24 months), self-reported health (assessed through the final item of the Italian version of the EuroQol EQ-D5L ${ }^{28}$ ) and possibly related serious adverse events. Adverse events were both self-reported and gathered from data obtained from the regional hospital discharge administrative database (Italian Scheda di Dimissione Ospedaliera) for the residents in the Abruzzo Region (46.0\% of the sample); and only self-reported for the rest of the sample. The details of the International Classification of Diseases, Ninth Revision, Clinical Modification (ICD-9-CM) codes used to extract adverse events are reported in the protocol ${ }^{27}$ and in the online supplementary material.

The differences by baseline cigarette use were evaluated using Kruskal-Wallis or one-way analysis of variance with Sidak correction for continuous variables, and $\chi^{2}$ test for categorical variables. For the latter, when more than two categories were compared (such as for cigarette use), separate comparisons were made for one group versus the others, and different $p$ values were computed. The difference in continuous variables (ie, number of cigarettes smoked per day) within groups between baseline and end of follow-up was evaluated through Wilcoxon matched-pairs signed-rank test.

Multivariable random-effect linear and logistic regressions, with geographical region as the cluster unit, were used to investigate potential predictors of continuous and categorical outcomes, respectively. We set eight multivariable models for the following outcomes: (A) tobacco smoking abstinence at 24 months; (B) abstinence from both tobacco smoking and e-cigarette use at 24 months; (C) possibly related serious adverse events at 24 months; (D) reduction by $\geq 50 \%$ of tobacco cigarette consumption from baseline to 24 months, by baseline cigarette use group (this model was fitted into two versions: the first included the whole sample of tobacco and dual users at baseline; the second included only the subsample of continuing smokers, excluding those who had quit and whose cigarette consumption was zero at follow-up); (E) reduction by $\geq 50 \%$ of tobacco cigarette consumption from baseline to 24 months, by 24-month cigarette use group (as most dual users switched to another group, this model and model $G$ were needed to further investigate the potential predictors of tobacco smoking reduction among the switchers); (F) difference in the daily number of tobacco cigarettes smoked per day at 24 months compared with baseline, by baseline cigarette use group (this model was fitted into two versions: the first included the whole sample of tobacco and dual users at baseline; the second included only the subsample of continuing smokers, excluding those who had quit and whose cigarette consumption was zero at follow-up); (G) difference in the daily number of tobacco cigarettes smoked per day at 24 months compared with baseline, by 24-month cigarette use group and $(\mathrm{H})$ difference in the self-rated health at 24 months compared with baseline. The users of e-cigarettes only at baseline were excluded from models D, E, F and G.

With the exceptions of models C, E and G, which included a limited number of successes and had to be fitted with a restricted set of covariates, for all other models the number of successes of categorical outcomes (excluding adverse events) approximated 10 successes for each recorded variable (thus avoiding overfitting requirements). ${ }^{29}$ It was thus decided a priori to include all recorded variables into all final models regardless of significance, unless inclusion would create multicollinearity or violate other assumptions. Each covariate was tested in its original form or transformed if needed: only the number of cigarettes smoked per day was transformed into its square root; because the results were similar to those with the covariate included in its untransformed version, it was thus kept in the model in its original form. Models A, B, D, F and $\mathrm{H}$ were adjusted for the following baseline characteristics: age, gender, body mass index, marital status, educational level, occupation, alcohol use, hypertension, hypercholesterolaemia, diabetes, selfrated health and years of tobacco smoking (former smoking for e-cigarette-only users). We excluded physical activity from the final multivariate models due to substantial missing data $(n=41)$ and its virtually null effect on any dependent variables. The number of tobacco cigarettes smoked per day was transformed to be included into models $\mathrm{A}, \mathrm{B}, \mathrm{C}$ and $\mathrm{H}$ : because no tobacco cigarettes were smoked at baseline by e-cigarette-only users, we recategorised the amount of smoking, using tertiles. Those smoking $<10$ tobacco cigarettes per day (or $<50$ puffs per day if e-cigarette-only smokers) at baseline were assigned to the lowest tertile of consumption; smokers of 10-19 tobacco cigarettes (or 50-100 puffs if e-cigarette-only users) per day at baseline were assigned to the intermediate tertile; smokers of 20 or more cigarettes (or 100 or more puffs if e-cigarette-only users) per day at baseline were classified into the highest tertile.

Potential interactions with the dependent variable and/or quadratic/cubic terms were investigated for all covariates. In logistic regression analyses, the outlier analysis was based on Pearson calculation and standardised residuals, the change in Pearson $\chi^{2}$, and Dbeta influence statistics and leverage (hat diagonal matrix). The validity of the final linear regression models was assessed as follows. The assumption of constant error variance was checked graphically, plotting Pearson residuals versus fitted values, and formally, using the Cook-Weisberg test for heteroscedasticity. High leverage observations were identified by computing Pearson, standardised and studentised residuals, Cook's D influence, Welsch distance and the hat diagonal matrix (LC Hamilton. Statistics with Stata: Version 12, Eighth Edition. Boston: Cengage 2013). We found $<30$ influential or high-leverage observations in all models. In all cases, we repeated the analyses excluding these observations, with no substantial changes, and we thus kept all observations in the models.

We had very few missing data for all outcome variables $(<5)$ except self-rated health, which was not answered by 56 participants at baseline (but only 30 of them were kept in the 24-month assessment), and by 3 participants at the 24-month follow-up. Models A, B, C and $\mathrm{H}$ were rerun without self-rated health at baseline ( -30 participants), with no appreciable variation, therefore it was retained. Model $\mathrm{H}$ was inevitably fitted with 33 missing observations. Given that the participants lost in model $\mathrm{H}$ were relatively few ( $3.5 \%$ of the sample) and balanced across baseline groups, no missing data imputation technique was adopted. Finally, the distribution of the difference in selfrated health was relatively skewed (Shapiro-Wilk $\mathrm{p}<0.01$ ) and model $\mathrm{G}$ was set also using its cubic form. However, again the estimates of $p$ values of cigarette use covariates were similar and the dependent variable was maintained in its original form to facilitate results interpretation.

The results of the logistic regression analyses are presented as ORs and the corresponding 95\% CIs whereas the results of the linear regression analyses are presented as $\beta$-coefficients and 95\% CIs. A two-tailed p value of 0.05 was considered significant for all analyses, which were performed using Stata V.13.1 (Stata Corp, College Station, Texas, USA, 2014). 


\section{RESULTS}

The flow of the participants is shown in figure 1 and baseline characteristics are reported in online supplementary table S1. After 24 months, $61.1 \%$ of the 229 baseline e-cigarette-only users were still abstinent from tobacco smoking; $23.1 \%$ of the 480 baseline tobacco smokers and $26.0 \%$ of the 223 baseline dual users achieved tobacco abstinence $(\mathrm{p}<0.001$ for e-cigarette-only users vs tobacco smokers or dual users; table 1). The proportion of participants who achieved complete abstinence (who were using neither tobacco cigarettes nor e-cigarettes) did not significantly differ by baseline use group: $18.8 \%, 17.5 \%$ and $14.3 \%$ among e-cigarette users, tobacco smokers and dual users, respectively (all $\mathrm{p}>0.05$ ).

The proportion of participants reducing tobacco cigarette consumption by $50 \%$ or more, or by $\geq 5$ tobacco cigarettes per day, and the average daily number of cigarettes, did not change by baseline group (table 1 ; all $\mathrm{p}>0.05$ ). Importantly, the majority $(83.4 \%)$ of dual users at baseline abandoned e-cigarettes and continued to smoke only tobacco $(57.4 \%)$, or quit tobacco $(11.7 \%)$ or both tobacco cigarettes and e-cigarettes (14.3\%) during follow-up (table 1). Therefore, a second analysis was conducted stratifying by baseline and 24-month cigarette use, in order to assess the variation of the pattern of consumption among the switchers as well. Among the 603 tobacco-only smokers or dual users at baseline, 21 of the $40(52.5 \%)$ participants who started or continued dual use during the follow-up reduced tobacco cigarette consumption by $\geq 50 \%$, while only 67 of the $489(13.7 \%)$ participants who started or continued only tobacco smoking showed a $\geq 50 \%$ cigarette reduction $(\mathrm{p}<0.001$, table 1).

No significant differences in average self-rated health were noted by baseline group (all $\mathrm{p}>0.05$ ). A substantial improvement, however, was observed for tobacco smokers or dual users who switched to e-cigarettes only $(+1.1$ or 1.0 in EuroQol mean score, respectively; $\mathrm{p}<0.05$; table 1 ).

We recorded an identical number of mouth irritations $(n=38)$ and possibly related serious adverse events $(n=38$; table 1$)$. Potential adverse events were reported by $4.4 \%, 2.9 \%$ and $6.3 \%$ of baseline e-cigarette users, tobacco smokers and dual users, respectively $(p<0.05$ for the comparison of tobacco smokers vs dual users). Mouth irritation rates were $6.1 \%, 4.2 \%$ and $1.8 \%$ in the above groups $(\mathrm{p}<0.05$ for the comparison of e-cigarette users vs dual users). The distribution of adverse events by baseline and 24-month group is reported in figure 1 . The characteristics of the participants reporting a serious adverse event, and its type, are reported in online supplementary table S2. Also, the cigarette use throughout the follow-up of the 38 participants experiencing a possibly related serious adverse event is shown in online supplementary figure S1. Notably, most tobacco-only smokers at baseline, who experienced an adverse event, remained tobacco-only smokers or quit both tobacco smoking and e-cigarette use. In contrast, most of the e-cigarette-only and dual users at baseline who experienced a serious adverse event $(n=24)$, switched group during the 24-month follow-up: 13 switched to tobacco smoking only, and 5 quit both tobacco cigarettes and e-cigarettes.

Multivariate analyses substantially confirmed univariate results (table 2): when several potential confounders were adjusted for, tobacco smoking abstinence remained significantly more likely among e-cigarette users (adjusted OR 5.56; 95\% CI 3.89 to $7.95 ; \mathrm{p}<0.001)$; the likelihood of abstinence from tobacco smoking and e-cigarette use, as well as self-reported health, did not significantly vary by baseline group $(p>0.05)$; the probability of halving or reducing the average number of daily tobacco cigarettes smoked did not change by baseline group, but tobacco smokers who started dual use or dual users

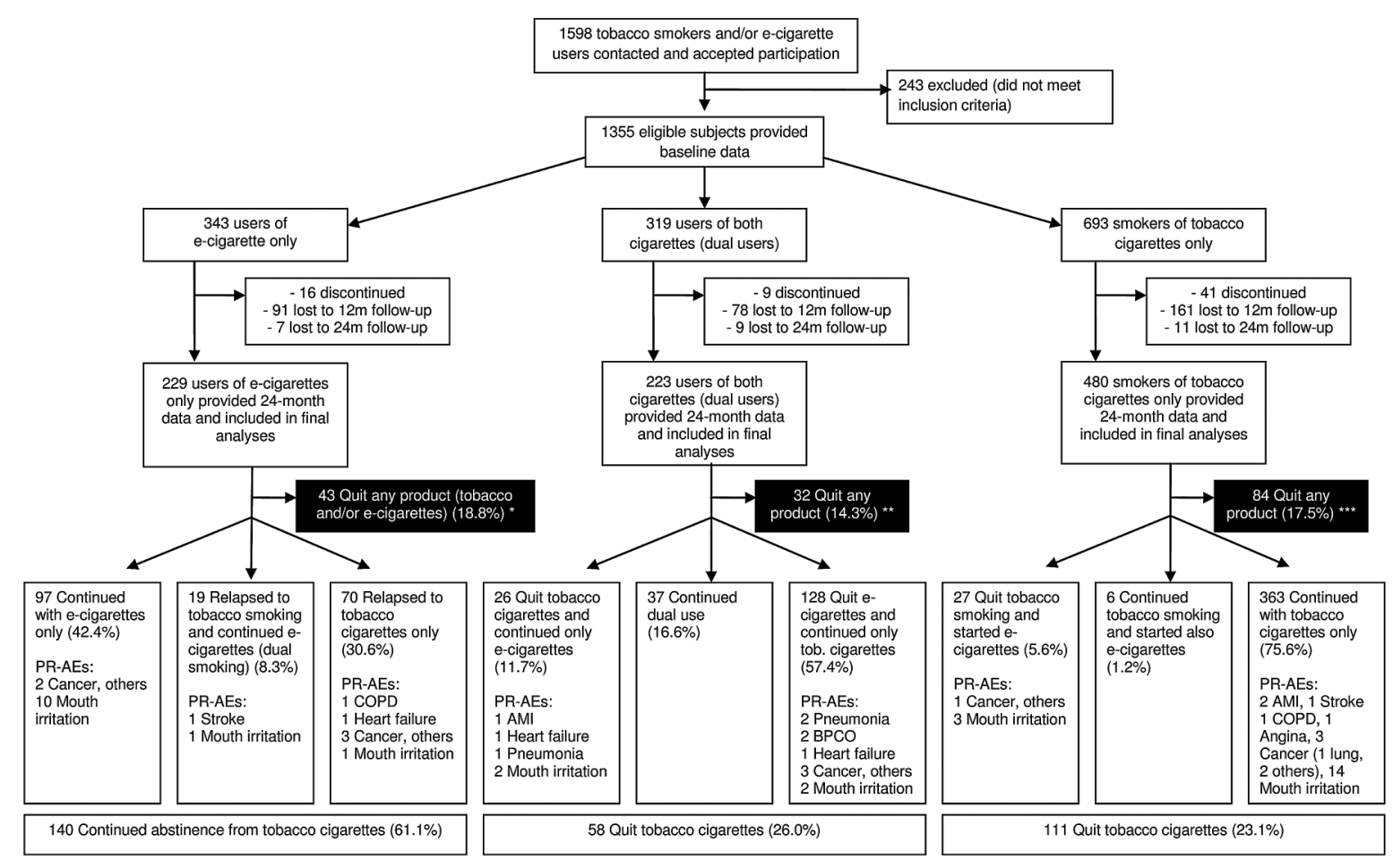

PR-AEs: Possibly related adverse events. AMI = Acute Myocardial infarction. COPD $=$ Chronic obstructive pulmonary diseases. * Among the 43 baseline users of e-cigarette only that quit all cigarettes, the following PR-AEs were observed: 1 AMl, 1 Cancer, others, 2 Mouth irritation. ${ }^{* \star}$ Among the 32 baseline dual users who quit all cigarettes, the following PR-AEs were observed: 1 COPD, 1 AMl,
Angina. ${ }^{* * *}$ Among the 84 baseline tobacco smokers only that quit all cigarettes, the following PR-AEs were observed: 2 COPD, 1 Pneumonia, 1 Stroke, 1 Hematological cancer, 3 Mouth irritation.

Figure 1 Flow of the participants, number of quitters and possibly related serious adverse events. 


\begin{tabular}{|c|c|c|c|c|c|c|}
\hline & \multicolumn{3}{|c|}{ Cigarette use at baseline } & \multirow[b]{2}{*}{ p Value ${ }^{A}$} & \multirow[b]{2}{*}{$p$ Value $^{B}$} & \multirow[b]{2}{*}{ p Value } \\
\hline & $\begin{array}{l}\text { E-cigarettes only } \\
(n=229)\end{array}$ & $\begin{array}{l}\text { Tobacco cigarettes only } \\
(\mathrm{n}=480)\end{array}$ & $\begin{array}{l}\text { Dual use } \\
(\mathrm{n}=223)\end{array}$ & & & \\
\hline \multicolumn{7}{|l|}{ 1. Cigarette use at 24 months } \\
\hline \multicolumn{7}{|l|}{ Tobacco cigarettes only, per cent $(n)$} \\
\hline $\begin{array}{l}\text { Continuous tobacco abstinence from baseline or cessation from tobacco } \\
\text { smoking during follow-up* }\end{array}$ & $61.1(140)$ & $23.1(111)$ & $26.0(58)$ & $<0.001$ & 0.4 & $<0.001$ \\
\hline Tobacco smoking (continued or relapsed) & $38.9(89)$ & $76.9(369)$ & $74.0(165)$ & $<0.001$ & 0.4 & $<0.001$ \\
\hline \multicolumn{7}{|l|}{ All product use (cigarettes and/or e-cigarettes), per cent (n) } \\
\hline Quit using any product (either tobacco and/or e-cigarette) & $18.8(43)$ & $17.5(84)$ & $14.3(32)$ & 0.7 & 0.3 & 0.20 \\
\hline Using e-cigarettes only & $42.4(97)$ & $5.6(27)$ & $11.7(26)$ & $<0.001$ & 0.004 & $<0.001$ \\
\hline Dual use (tobacco cigarettes and e-cigarettes) & $8.3(19)$ & $1.3(6)$ & $16.6(37)$ & $<0.001$ & $<0.001$ & 0.007 \\
\hline Smoking tobacco cigarettes only & $30.6(70)$ & $75.6(363)$ & $57.4(128)$ & $<0.001$ & $<0.001$ & $<0.001$ \\
\hline \multicolumn{7}{|l|}{ 2. Number of tobacco cigarettes } \\
\hline \multicolumn{7}{|l|}{ Mean number of tobacco cigarettes daily at 24 months (SD) } \\
\hline Stratified by baseline group & - & $10.0(8.4)$ & $11.2(9.8)$ & - & 0.09 & - \\
\hline \multicolumn{7}{|l|}{ Stratified by cigarette use at 24 months } \\
\hline Started or continued tobacco cigarettes only & $0.0(0.0)$ & $14.8(8.1)$ & $15.8(9.1)$ & - & 0.2 & - \\
\hline \multirow[t]{2}{*}{ Started or continued dual use only } & $0.0(0.0)$ & $19.0(6.3)$ & $14.0(9.5)$ & - & 0.2 & - \\
\hline & & $(\mathrm{p}=0.2) \dagger$ & $(p=0.3) \ddagger$ & & & \\
\hline \multicolumn{7}{|c|}{ Percentage of participants reducing tobacco cigarettes of $50 \%$ or more from baseline to 24 months } \\
\hline Stratified by baseline group & - & 34.5 & 39.7 & - & 0.2 & - \\
\hline \multicolumn{7}{|l|}{ Stratified by product use at 24 months } \\
\hline Started or continued tobacco cigarettes only & - & $14.1(n=51)$ & $9.4(n=12)$ & - & 0.2 & - \\
\hline \multirow[t]{2}{*}{ Started or continued dual use only } & - & $66.7(n=4)$ & $50.0(n=17)$ & - & 0.5 & - \\
\hline & & $(p<0.001) \dagger$ & $(p<0.001) \ddagger$ & & & \\
\hline \multicolumn{7}{|c|}{ Percentage of participants who smoked $\geq 5$ tobacco cigarettes less between baseline and 24 months } \\
\hline Stratified by baseline group & - & 38.6 & 42.5 & - & 0.3 & - \\
\hline \multicolumn{7}{|l|}{ Stratified by product use at 24 months } \\
\hline Started or continued tobacco cigarettes only & - & $23.5(n=85)$ & $22.1(\mathrm{n}=28)$ & - & 0.7 & - \\
\hline Started or continued dual use only & - & $66.7(n=4)$ & $55.9(n=19)$ & - & 0.6 & - \\
\hline \multicolumn{7}{|c|}{ Mean difference in the daily number of tobacco cigarettes between 24 months and baseline (SD) } \\
\hline Stratified by baseline group & - & $-4.1(8.1)$ & $-4.0(11.8)$ & - & 0.9 & - \\
\hline \multicolumn{7}{|l|}{ Stratified by product use at 24 months } \\
\hline Started or continued tobacco cigarettes only & - & $-1.6(6.4)$ & $-0.8(9.6)$ & - & 0.2 & - \\
\hline \multirow[t]{2}{*}{ Started or continued dual use only } & - & $-5.3(3.3)$ & $-6.5(10.7)$ & - & 0.8 & - \\
\hline & & $(\mathrm{p}=0.2) \dagger$ & $(\mathrm{p}=0.003) \neq$ & & & \\
\hline \multicolumn{7}{|l|}{ 3. Self-rated health $\S$-Mean difference between 24 months and baseline (SD) } \\
\hline Stratified by baseline group & $0.0(1.7)$ & $0.0(1.4)$ & $-0.1(1.7)$ & 0.9 & 0.4 & 0.5 \\
\hline \multicolumn{7}{|l|}{ Stratified by product use at 24 months } \\
\hline Quit using any product (either tobacco and/or e-cigarette) & $+0.2(1.6)$ & $+0.3(1.4)$ & $-0.2(2.1)$ & 0.7 & 0.14 & 0.4 \\
\hline Using e-cigarettes only & $+0.3(1.4)$ & $+1.1(1.7)$ & $+1.0(1.6)$ & 0.014 & 0.8 & 0.03 \\
\hline Dual use (tobacco cigarettes and e-cigarettes) & $-0.3(1.7)$ & $+0.3(1.5)$ & $+0.2(1.7)$ & 0.4 & 0.9 & 0.3 \\
\hline Smoking tobacco cigarettes only & $-0.5(1.9)$ & $-0.1(1.4)$ & $-0.4(1.4)$ & 0.041 & 0.039 & 0.7 \\
\hline \multicolumn{7}{|l|}{ 4. Safety—possibly related sAEs, per cent (n) } \\
\hline \multicolumn{7}{|l|}{ Stratified by baseline group } \\
\hline Mouth irritation & $6.1(14)$ & $4.2(20)$ & $1.8(4)$ & 0.27 & 0.10 & 0.019 \\
\hline
\end{tabular}




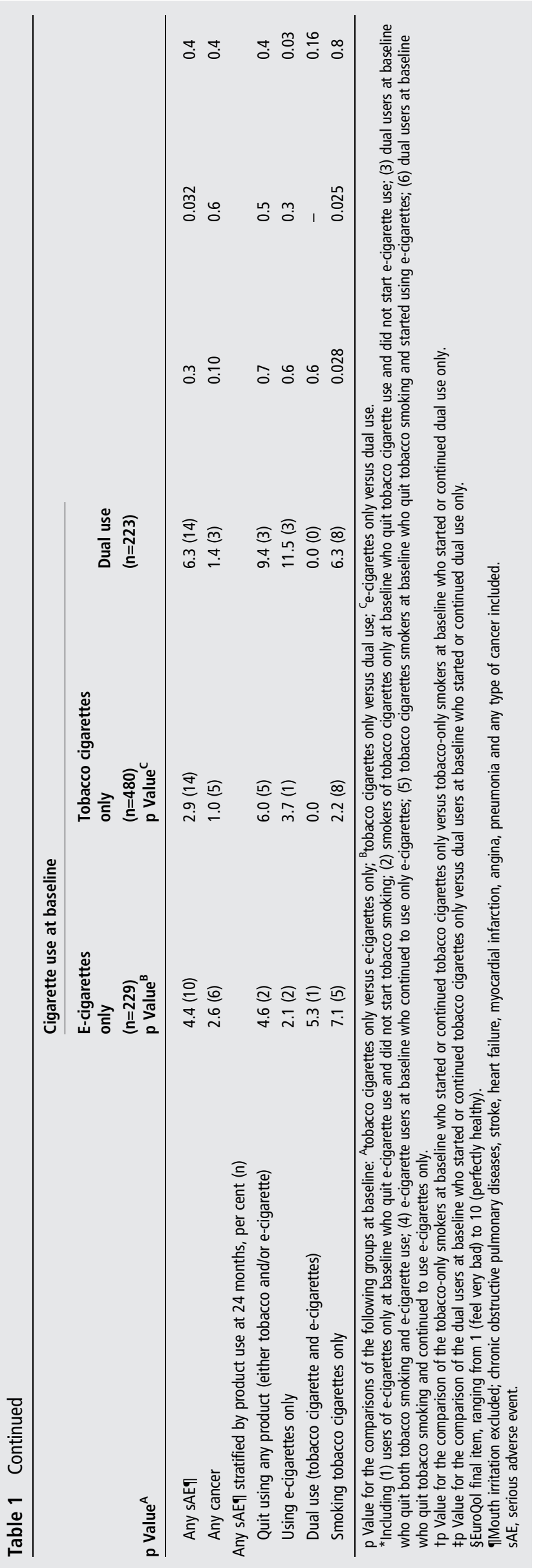

who continued dual using, were significantly more likely to halve their tobacco cigarette consumption and to decrease the average number of cigarettes per day than those who started or continued only smoking tobacco (all $\mathrm{p}<0.001$ ); dual users at baseline remained significantly more likely to report a serious adverse event than tobacco-only smokers (OR 2.40; 95\% CI 1.09 to $5.26 ; \mathrm{p}=0.029)$.

\section{Switching or quitting cigarette use}

Overall, 435 participants switched $(n=276 ; 29.6 \%)$ or stopped $(\mathrm{n}=159 ; 17.1 \%)$ using either product (tobacco cigarettes or e-cigarettes) during the follow-up (figure 1 and table 3). Very few tobacco cigarette smokers switched to dual use $(5.6 \%)$ or to e-cigarettes only (1.3\%). In contrast, only $16.6 \%$ of dual users remained dual users after 24 months, and most of them (57.4\%) abandoned e-cigarettes and continued to smoke only tobacco cigarettes. Thirty-nine per cent of e-cigarette-only users switched to tobacco smoking, while $42.4 \%$ continued with ecigarettes only or stopped using either tobacco cigarettes or e-cigarettes.

Of the 159 participants who quit using either product at 24 months, 91 had quit at the 12-month follow-up (57.2\%). Of the 131 participants who quit using either product at 12 months, 6 were lost to follow-up, 91 remained abstinent and 34 relapsed (27.2\%): 29 to tobacco smoking only, 4 to e-cigarettes only and 1 to dual use. Similar results were observed for quitting tobacco cigarettes (table 3 ).

Other secondary findings on $\mathrm{CO}$ levels, the other predictors of tobacco smoking, and abstinence from tobacco cigarettes and e-cigarettes, and adverse events, are reported in the online supplementary material.

\section{DISCUSSION}

To date, this is the only study to directly compare smokers of tobacco cigarettes only with users of e-cigarettes only, and to provide safety data on e-cigarette-only users for $>12$ months. With respect to the first year of follow-up, the analyses after the second year provided some important confirmations and some new insights.

This confirms that complete switching to e-cigarettes may help tobacco quitters remain abstinent from smoking: after 24 months the rate of relapse to tobacco smoking remained relatively low (38.9\%), if compared with the $60-90 \%$ relapse rates of tobacco cigarette smokers observed in population-based studies. ${ }^{30}$ It should be kept in mind that all e-cigarette users in our sample were former tobacco smokers at baseline, with a mean time of 8 months since switching to e-cigarettes. Notably, the analysis of those who had quit tobacco smoking at 12 months showed that the relapse rates to tobacco smoking at 24 months were also relatively low for tobacco-only smokers (30.3\%; table 3). With regard to safety, the rate of adverse events was not lower in e-cigarette-only users than in tobacco smokers, which was expected in this phase of the study, given that the excess risk of tobacco smoking takes $1-5$ years to substantially decrease. $^{31} 32$

The results also confirmed that the use of e-cigarettes in addition to tobacco smoking (dual use) does not seem to encourage tobacco smokers to quit tobacco. Further, dual users at baseline did not differ from tobacco-only smokers in tobacco cigarette consumption and self-rated health. However, the vast majority of dual users switched to another use status during the follow-up, which suggests that dual use is generally a transient phase rather than a long-term pattern of use. Further, the analyses stratified by baseline status may provide limited 


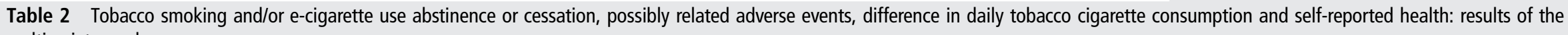
multivariate analyses

\begin{tabular}{|c|c|c|c|c|}
\hline Outcomes at 24 months & Adjusted OR $(95 \% \mathrm{Cl})$ & $\mathrm{p}$ Value & Crude OR $(95 \% \mathrm{Cl})$ & $\mathrm{p}$ Value \\
\hline \multicolumn{5}{|c|}{ Continuous tobacco abstinence from baseline or quit tobacco smoking during follow-up*,$\dagger$} \\
\hline Tobacco cigarettes only at baseline & 1 (ref cat) & - & 1 (ref cat) & - \\
\hline E-cigarettes only at baseline & 5.56 (3.89 to 7.95$)$ & $<0.001$ & $5.23(3.72$ to 7.35$)$ & $<0.001$ \\
\hline $\begin{array}{l}\text { Both tobacco and e-cigarettes at } \\
\text { baseline }\end{array}$ & 1.25 (0.85 to 1.84$)$ & 0.2 & 1.17 (0.81 to 1.69$)$ & 0.4 \\
\hline \multicolumn{5}{|c|}{ Quit all cigarettes (electronic and/or traditional)* } \\
\hline Tobacco cigarettes only at baseline & 1 (ref cat) & - & 1 (ref cat) & - \\
\hline E-cigarettes only at baseline & $1.12(0.73$ to 1.72$)$ & 0.6 & 1.09 (0.73 to 1.64$)$ & 0.7 \\
\hline $\begin{array}{l}\text { Both tobacco and e-cigarettes at } \\
\text { baseline }\end{array}$ & 0.94 (0.59 to 1.49 ) & 0.8 & 0.79 (0.51 to 1.23$)$ & 0.3 \\
\hline \multicolumn{5}{|l|}{ Safety-possibly related sAEs $\ddagger$} \\
\hline Tobacco cigarettes only at baseline & 1 (ref cat) & - & 1 (ref cat) & - \\
\hline E-cigarettes only at baseline & $1.48(0.63$ to 3.47$)$ & 0.4 & 1.52 (0.66 to 3.48$)$ & 0.3 \\
\hline $\begin{array}{l}\text { Both tobacco and e-cigarettes at } \\
\text { baseline }\end{array}$ & 2.40 (1.09 to 5.26$)$ & 0.029 & 2.23 (1.04 to 4.76$)$ & 0.038 \\
\hline \multicolumn{5}{|c|}{ Reduction of tobacco cigarette consumption by $50 \%$ or more from baseline to 24 months§ } \\
\hline Tobacco cigarettes only at baseline & 1 (ref cat) & - & 1 (ref cat) & - \\
\hline $\begin{array}{l}\text { Both tobacco and e-cigarettes at } \\
\text { baseline }\end{array}$ & $\begin{array}{l}1.28(0.90 \text { to } 1.82) \text { 9 } \\
0.99(0.57 \text { to } 1.71)^{* *}\end{array}$ & $\begin{array}{l}0.2 \\
0.9\end{array}$ & $\begin{array}{l}1.25(0.89 \text { to } 1.76) \text { 9 } \\
1.25(0.76 \text { to } 2.05)^{* *}\end{array}$ & $\begin{array}{l}0.2 \\
0.4\end{array}$ \\
\hline \multicolumn{5}{|c|}{ Reduction of tobacco cigarette consumption by $50 \%$ or more from baseline to 24 monthst $\dagger$} \\
\hline $\begin{array}{l}\text { Tobacco or dual users at baseline } \\
\text { who switched to or continued with } \\
\text { tobacco smoking only }\end{array}$ & 1 (ref cat) & - & 1 (ref cat) & - \\
\hline \multirow[t]{2}{*}{$\begin{array}{l}\text { Tobacco or dual users at baseline } \\
\text { who started or continued dual use }\end{array}$} & $8.48(4.05$ to 17.8$)$ & $<0.001$ & 7.47 (3.81 to 14.7$)$ & $<0.001$ \\
\hline & Adjusted coefficient $(95 \% \mathrm{Cl})$ & & Raw coefficient $(95 \% \mathrm{Cl})$ & \\
\hline \multicolumn{5}{|c|}{ Difference in the daily number of tobacco cigarettes from 24 months to baseline $\ddagger \ddagger$} \\
\hline Tobacco cigarettes only at baseline & 0 (ref cat) & - & 0 (ref cat) & - \\
\hline $\begin{array}{l}\text { Both tobacco and e-cigarettes at } \\
\text { baseline }\end{array}$ & $\begin{array}{l}0.44(-0.88 \text { to } 1.75) \text { ฯ } \\
0.75(-1.13 \text { to } 2.63)^{* *}\end{array}$ & $\begin{array}{l}0.5 \\
0.4\end{array}$ & $\begin{array}{l}0.10(-1.41 \text { to } 1.61) \text { 9 } \\
0.87(-0.42 \text { to } 2.15)^{* *}\end{array}$ & $\begin{array}{l}0.9 \\
0.2\end{array}$ \\
\hline \multicolumn{5}{|c|}{ Difference in the daily number of tobacco cigarettes from 24 months to baseline§§ } \\
\hline $\begin{array}{l}\text { Tobacco smokers who continued } \\
\text { only smoking and dual users at } \\
\text { baseline who switched to tobacco } \\
\text { only smoking }\end{array}$ & 0 (ref cat) & - & 0 (ref cat) & - \\
\hline $\begin{array}{l}\text { Dual users at baseline who } \\
\text { continued dual use and } \\
\text { tobacco-only smokers who } \\
\text { switched to dual use }\end{array}$ & $-5.71(-8.02$ to -3.39$)$ & $<0.001$ & $-5.32(-7.80$ to -2.85$)$ & $<0.001$ \\
\hline \multicolumn{5}{|c|}{ Difference in the self-reported health score from 24 months to baselineqा? } \\
\hline Tobacco cigarettes only at baseline & 0 (ref cat) & - & 0 (ref cat) & - \\
\hline E-cigarettes only at baseline & $0.14(-0.08$ to 0.35$)$ & 0.2 & $-0.03(-0.27$ to 0.22$)$ & 0.8 \\
\hline
\end{tabular}


Both tobacco cigarettes and

e-cigarettes at baseline

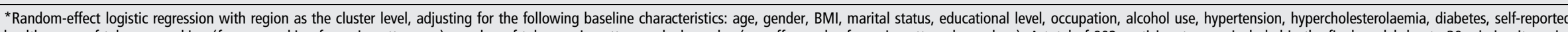

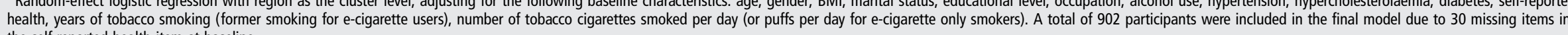
the self-reported health item at baseline.

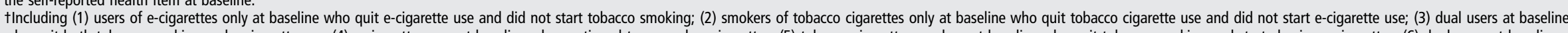

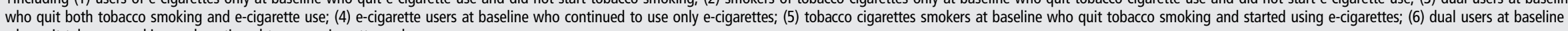
who quit tobacco smoking and continued to use e-cigarettes only.

FRandom-effect logistic regression with region as the cluster level, adjusting for age, baseline self-reported health and quitting all smoking during the 24-month follow-up.

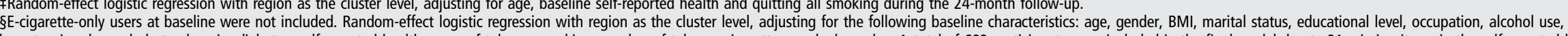

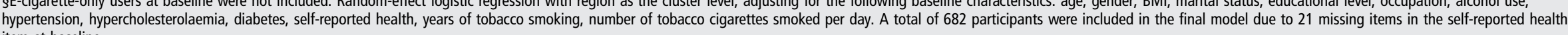
item at baseline.

IComputed from a model that included the whole sample of tobacco and dual smokers at baseline.

**Computed from a model that included only the subsample of baseline smokers who continued smoking at 24 months (excluding those who had quit and whose cigarette consumption was zero at follow-up).

†tRestricted to tobacco only smokers or dual users at baseline who did not quit or switch to e-cigarettes only ( $n=529)$. Random-effect logistic regression with region as the cluster level, adjusting for the following baseline characteristics: age, gender, self-reported health, years of tobacco smoking, number of tobacco cigarettes smoked per day.

¥¥E-cigarette-only users at baseline were not included. Random-effect linear regression with region as the cluster level, adjusting for the following baseline characteristics: age, gender, BMI, marital status, educational level, occupation, alcohol use,

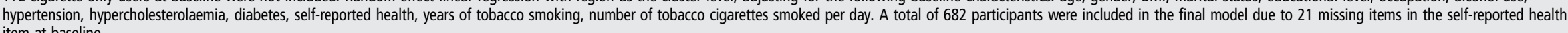
item at baseline.

$\S \S R e s t r i c t e d$ to tobacco-only smokers or dual users at baseline who did not quit or switch to e-cigarettes only $(\mathrm{n}=529)$. Random-effect linear regression with region as the cluster level, adjusting for the following baseline characteristics: age, gender, self-reported health, years of tobacco smoking, number of tobacco cigarettes smoked per day.

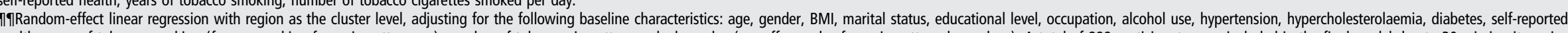

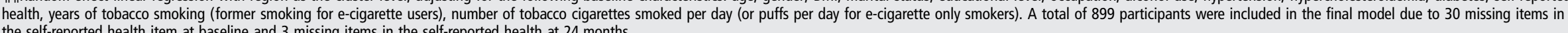
the self-reported health item at baseline and 3 missing
BMI, body mass index; SAEs, serious adverse events.

$$
\text { BMI, body mass index, SAES, serious adverse events. }
$$
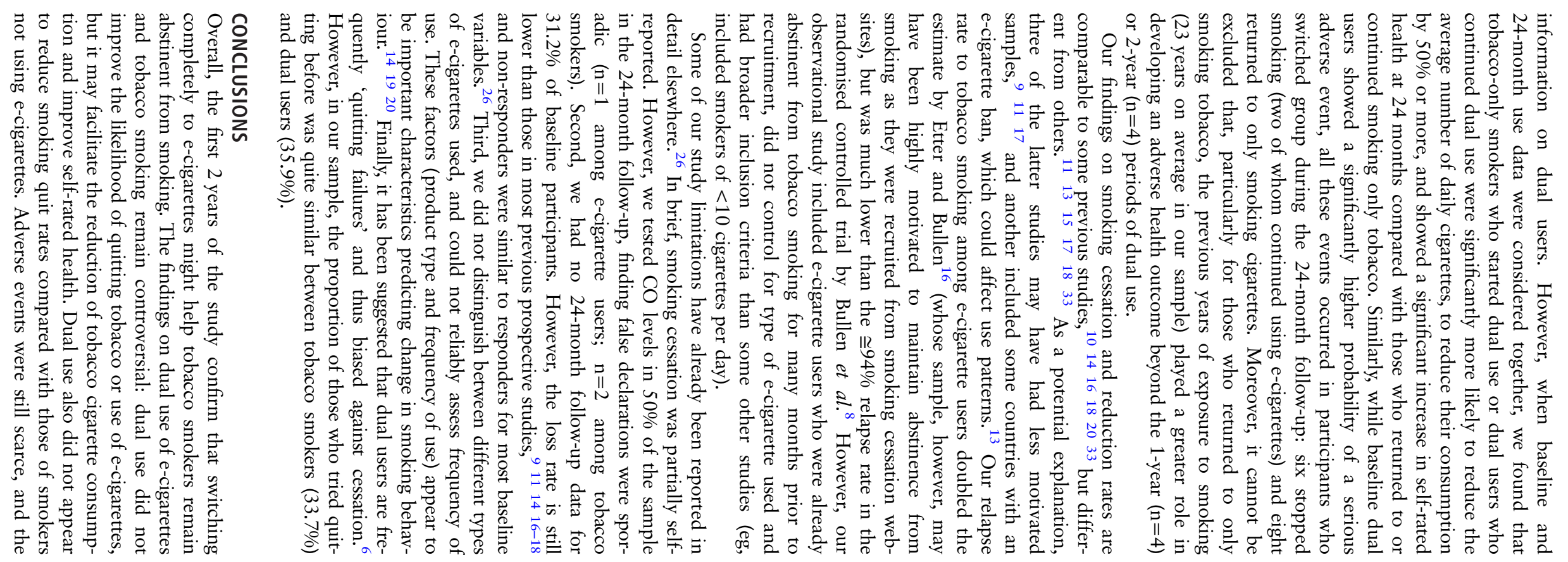
Table 3 Quitting and switching cigarette use during follow-up

\begin{tabular}{|c|c|c|c|}
\hline & \multicolumn{3}{|c|}{ Cigarette use at baseline } \\
\hline & $\begin{array}{l}\text { E-cigarettes only } \\
(n=229)\end{array}$ & $\begin{array}{l}\text { Tobacco cigarettes only } \\
(n=480)\end{array}$ & $\begin{array}{l}\text { Dual use } \\
(n=223)\end{array}$ \\
\hline Switching to another product use group at 24 months & $(n=229)$ & $(n=480)$ & $(n=223)$ \\
\hline No switch & 42.4 & 75.6 & 16.6 \\
\hline Switch to no product use & 18.8 & 17.5 & 14.3 \\
\hline Switch from e-cigarettes only to dual use or tobacco-only smoking & 38.9 & - & - \\
\hline Switch from dual use or tobacco-only smoking to e-cigarettes only & - & 5.6 & 11.7 \\
\hline Switch from dual use to tobacco-only smoking & - & - & 57.4 \\
\hline Switch from tobacco only to dual use & - & 1.3 & - \\
\hline \multicolumn{4}{|l|}{ Quitting all product use } \\
\hline Quit all product use* at 12 months $(n=125)$ & $(n=34)$ & $(n=65)$ & $(n=26)$ \\
\hline Remained abstinent from both tobacco cigarettes and e-cigarettes at 24 months & 76.5 & 72.3 & 69.2 \\
\hline Relapsed to either tobacco and/or e-cigarettes at 24 months & 23.5 & 27.7 & 30.8 \\
\hline Tobacco smoking quitters at 12 months $(n=106)$ & $(n=0)$ & $(n=69)$ & $(n=37)$ \\
\hline Remained abstinent from smoking at 24 months & - & 69.7 & 74.0 \\
\hline Relapsed to tobacco smoking at 24 months & - & 30.3 & 26.0 \\
\hline
\end{tabular}

next years of follow-up will help clarify safety concerns, which remain the most important issue to support policies on e-cigarettes use.

\section{What this paper adds}

- Despite the potential public health relevance, the current evidence on long-term safety and efficacy/effectiveness of e-cigarettes is scarce and conflicting.

- After 24 months of a prospective follow-up, most users of e-cigarettes alone were able to remain abstinent from tobacco smoking.

- Dual use of e-cigarettes with tobacco cigarettes did not encourage quitting tobacco or e-cigarette use, but may be helpful to reduce tobacco consumption.

\footnotetext{
Author affiliations

${ }^{1}$ Department of Medicine and Aging Sciences, University of Chieti, Chieti, Italy

${ }^{2}$ Local Health Unit of Pescara, Pescara, Italy

3"University G. d'Annunzio" Foundation, Chieti, Italy

${ }^{4}$ Regional Healthcare Agency of Abruzzo, Pescara, Italy

${ }^{5}$ Department "G. F. Ingrassia" - Hygiene and Public Health, University of Catania, Catania, Italy

${ }^{6}$ Department of Clinical Sciences and Community Health, University of Milan, Milan, Italy

${ }^{7}$ Department of Public Health Sciences, University of Turin, Turin, Italy

${ }^{8}$ Italian National Institute of Health, Rome, Italy

${ }^{9}$ Institute of Public Health, Università Cattolica del Sacro Cuore, Rome, Largo Francesco Vito, Roma, Italy

${ }^{10}$ Department of Public Health and Infectious Diseases, Sapienza University of Rome, Roma, Italy
}

Acknowledgements Although their contribution has been substantial, some of the authors have been listed as ISLESE (Italian Study on Long-term E-cigarette Safety and Efficacy) Working Group, including Maria Rosaria Gualano (University of Turin, Italy), Giancarlo Cicolini (Local Health Unit of Lanciano-Vasto-Chieti, Italy), Giorgia Fragassi (University of Chieti, Italy), Giorgio Liguori (University Parthenope of Naples) and Stefania Boccia (Università Cattolica del Sacro Cuore, Rome). The investigators are also grateful to Dr Serena Di Sante, Giorgia Di Sante, the students of the Faculty of Medicine of Catania and general practitioners from Abruzzo (Francesco Di Silvestro, Luciano Giacci, Marino Mincone, Gabriella Salladini, Giuliano Salvio, Renato Seller, Lucio Zinni) for their help during recruitment.
Collaborators Maria Rosaria Gualano (Department of Public Health Sciences, University of Turin, Turin, Italy); Giancarlo Cicolini (Local Health Unit of Lanciano-Vasto-Chieti, Chieti, Italy); Giorgia Fragassi (Department of Medicine and Aging Sciences, University of Chieti, Chieti, Italy); Giorgio Liguori (Department of Movement Sciences and Wellbeing, University Parthenope of Neaples, Neaples, Italy); Stefania Boccia (Institute of Public Health, Università Cattolica del Sacro Cuore, Rome, Italy).

Contributors All the authors and the collaborators participated in the design, analysis and interpretation of the study. LM, MEF, CLV, RS, WR, MFi and PV were involved in all phases of the study. MFe and CM collected baseline and follow-up data, and participated in data-analysis. LM and MEF tested CO levels, linked hospital admissions and wrote the manuscript. LM is the guarantor for all data.

Funding The first 2 years of the study were unfunded. The next 3 years of follow-up are going to be funded through crowdfunding (Kickstarter project titled 'E-cigarette long-term efficacy \& safety: a study to complete'). Besides seven authors (MEF, RS, MRG, GL, MFi, PV, CM) and seven anonymous contributors, who donated a total of $€ 515$ and $€ 80$, respectively, all other contributors are private citizens. The authors are indebted to all of them: Mattia Brescianini, Necdet Yucel, Giuseppe Prosperini, Giancarlo Cicolini, Ludovica Rotunno, Annalisa Esposito, Cristina Naccarato, Phuong Pham, Giorgia Fragassi, Giorgio Salvatore, Maria Grazia D'Agati, Giacomo Manzoli, Eliseo Torrez, Cheng Kin Phang, Ryan White, Placido D'Agati, Fabrizio Bert, Macz Yaemmaneechai, Felice lossa, Lu Gedge, Carol Long, Patrick Murphy, Jeff Mundine, Lucia Manzoli, Martin Smith, Julien Malfroy, Taylor Darsey, Sam Lewis, Jeff George and Alexander van der Wal.

Competing interests None declared.

Patient consent Obtained.

Ethics approval Ethics Committee of the University of Chieti.

Provenance and peer review Not commissioned; externally peer reviewed.

Data sharing statement The raw data set is available from the corresponding author on request.

Open Access This is an Open Access article distributed in accordance with the Creative Commons Attribution Non Commercial (CC BY-NC 4.0) license, which permits others to distribute, remix, adapt, build upon this work non-commercially, and license their derivative works on different terms, provided the original work is properly cited and the use is non-commercial. See: http://creativecommons.org/ licenses/by-nc/4.0/

\section{REFERENCES}

1 Chang AY, Barry M. The global health implications of e-cigarettes. JAMA 2015;314:663-4.

2 Manzoli L, Boccia S. Electronic cigarettes: scarce data and divergent legislations. The need for evidence-based health policies and research funding. Eur J Public Health Published Online First: 1 Oct 2015. doi:10.1093/eurpub/ckv179

3 McKee M, Capewell S. Evidence about electronic cigarettes: a foundation built on rock or sand? BMJ 2015;351:h4863. 
4 Gualano MR, Passi S, Bert F, et al. Electronic cigarettes: assessing the efficacy and the adverse effects through a systematic review of published studies. I Public Health (Oxf) 2015;37:488-97.

5 Hajek P. Electronic cigarettes have a potential for huge public health benefit. BMC Med 2014;12:225.

6 McRobbie H, Bullen C, Hartmann-Boyce J, et al. Electronic cigarettes for smoking cessation and reduction. Cochrane Database Syst Rev 2014;12:CD010216.

7 Pisinger C, Dossing M. A systematic review of health effects of electronic cigarettes. Prev Med 2014;69:248-60.

8 Bullen $C$, Howe $C$, Laugesen $M$, et al. Electronic cigarettes for smoking cessation: a randomised controlled trial. Lancet 2013;382:1629-37.

9 Caponnetto P, Campagna D, Cibella F, et al. EffiCiency and Safety of an eLectronic cigAreTte (ECLAT) as tobacco cigarettes substitute: a prospective 12-month randomized control design study. PLOS ONE 2013;8:e66317.

10 Polosa R, Caponnetto P, Morjaria JB, et al. Effect of an electronic nicotine delivery device (e-Cigarette) on smoking reduction and cessation: a prospective 6-month pilot study. BMC Public Health 2011;11:786.

11 Polosa R, Morjaria JB, Caponnetto P, et al. Effectiveness and tolerability of electronic cigarette in real-life: a 24-month prospective observational study. Intern Emerg Med 2014;9:537-46.

12 Adriaens $K$, Van Gucht D, Declerck $P$, et al. Effectiveness of the electronic cigarette: an eight-week Flemish study with six-month follow-up on smoking reduction, craving and experienced benefits and complaints. Int J Environ Res Public Health 2014:11:11220-48

13 Adkison SE, O'Connor RJ, Bansal-Travers M, et al. Electronic nicotine delivery systems: international tobacco control four-country survey. Am I Prev Med 2013;44:207-15.

14 Biener L, Hargraves JL. A longitudinal study of electronic cigarette use in a population-based sample of adult smokers: association with smoking cessation and motivation to quit. Nicotine Tob Res 2015;17:127-33.

15 Choi K, Forster JL. Beliefs and experimentation with electronic cigarettes: a prospective analysis among young adults. Am J Prev Med 2014;46:175-8.

16 Etter JF, Bullen C. A longitudinal study of electronic cigarette users. Addict Behav 2014;39:491-4.

17 Grana RA, Popova L, Ling PM. A longitudinal analysis of electronic cigarette use and smoking cessation. JAMA Intern Med 2014;174:812-13.

18 Vickerman KA, Carpenter KM, Altman T, et al. Use of electronic cigarettes among state tobacco cessation quitline callers. Nicotine Tob Res 2013;15:1787-91.

19 Brose LS, Hitchman SC, Brown J, et al. Is the use of electronic cigarettes while smoking associated with smoking cessation attempts, cessation and reduced cigarette consumption? A survey with a 1-year follow-up. Addiction 2015;110:1160-8.

20 Hitchman SC, Brose LS, Brown J, et al. Associations between e-cigarette type, frequency of use, and quitting smoking: findings from a longitudinal online panel survey in Great Britain. Nicotine Tob Res 2015;17:1187-94.

21 Al-Delaimy WK, Myers MG, Leas EC, et al. E-cigarette use in the past and quitting behavior in the future: a population-based study. Am J Public Health 2015;105:1213-19.

22 Pearson JL, Stanton CA, Cha S, et al. E-cigarettes and smoking cessation: insights and cautions from a secondary analysis of data from a study of online treatment-seeking smokers. Nicotine Tob Res 2015;17:1219-27.

23 Sutfin EL, Reboussin BA, Debinski B, et al. The impact of trying electronic cigarettes on cigarette smoking by college students: a prospective analysis. Am J Public Health 2015;105:e83-9.

24 Rahman MA, Hann N, Wilson A, et al. E-cigarettes and smoking cessation: evidence from a systematic review and meta-analysis. PLOS ONE 2015;10: e0122544

25 Kalkhoran S, Glantz SA. E-cigarettes and smoking cessation in real-world and clinical settings: a systematic review and meta-analysis. Lancet Respir Med 2016;4:116-28

26 Manzoli L, Flacco ME, Fiore M, et al. Electronic cigarettes efficacy and safety at 12 months: cohort study. PLOS ONE 2015;10:e0129443.

27 Manzoli L, La Vecchia C, Flacco ME, et al. Multicentric cohort study on the long-term efficacy and safety of electronic cigarettes: study design and methodology. BMC Public Health 2013;13:883.

28 Savoia E, Fantini MP, Pandolfi PP, et al. Assessing the construct validity of the Italian version of the EQ-5D: preliminary results from a cross-sectional study in North Italy. Health Qual Life Outcomes 2006:4:47.

29 Stoltzfus JC. Logistic regression: a brief primer. Acad Emerg Med 2011;18:1099-104.

30 Krall EA, Garvey AJ, Garcia RI. Smoking relapse after 2 years of abstinence: findings from the VA Normative Aging Study. Nicotine Tob Res 2002;4:95-100.

31 Ahmed AA, Patel K, Nyaku MA, et al. Risk of heart failure and death after prolonged smoking cessation: role of amount and duration of prior smoking. Circ Heart Fail 2015;8:694-701.

32 Kenfield SA, Stampfer MJ, Rosner BA, et al. Smoking and smoking cessation in relation to mortality in women. JAMA 2008;299:2037-47.

33 Caponnetto $\mathrm{P}$, Auditore R, Russo C, et al. Impact of an electronic cigarette on smoking reduction and cessation in schizophrenic smokers: a prospective 12-month pilot study. Int J Environ Res Public Health 2013;10:446-61. 